\title{
MATHEMATICAL PERSPECTIVES
}

BULLETIN (New Series) OF THE

AMERICAN MATHEMATICAL SOCIETY

Volume 50, Number 4, October 2013, Pages 629-639

S 0273-0979(2013)01416-2

Article electronically published on June 10, 2013

\section{ABOUT THE COVER: KEPLER AND THE RUDOLPHINE TABLES}

\author{
MIKAEL RÅGSTEDT
}

Around the year 1600, a rare but most fortunate constellation occurred. Not in the sky this time, but in the city of Prague. It consisted of three men whose destinies by chance crossed there and then. They could not be more different as to their origins, life stories, and careers, as well as to their characters, temperaments, and expectations. But they all played their parts in what would almost thirty years later result in a long-awaited publication, the Tabulae Rudolphinae, or the Rudolphine Tables. The three men were:

- Rudolph II, the Holy Roman Emperor and patron whose name is in the title;

- Tycho Brahe, who had performed and collected the best astronomical observations the world ever saw before the telescope;

- Johannes Kepler, the author of the book, who out of these observations managed to put an end to the old obvious truth that planets move uniformly in circles.

The Danish Protestant nobleman Tycho Brahe had been awarded the island of Ven in the strait separating today's Sweden and Denmark. There he erected a castle together with the best equipped observatories available. He understood that systematically higher precision was necessary to comprehend how the planets moved. After twenty years of recorded observations on an almost industrial scale, the haughty aristocrat fell into political disfavour with the young, rising Danish king and had to abandon his island.

In this period the Holy Roman Emperor resided in Prague. Rudolph II was senior to all the other Roman Catholic monarchs. He was a patron of the arts and

Received by the editors March 20, 2013.

(C)2013 American Mathematical Society Reverts to public domain 28 years from publication 


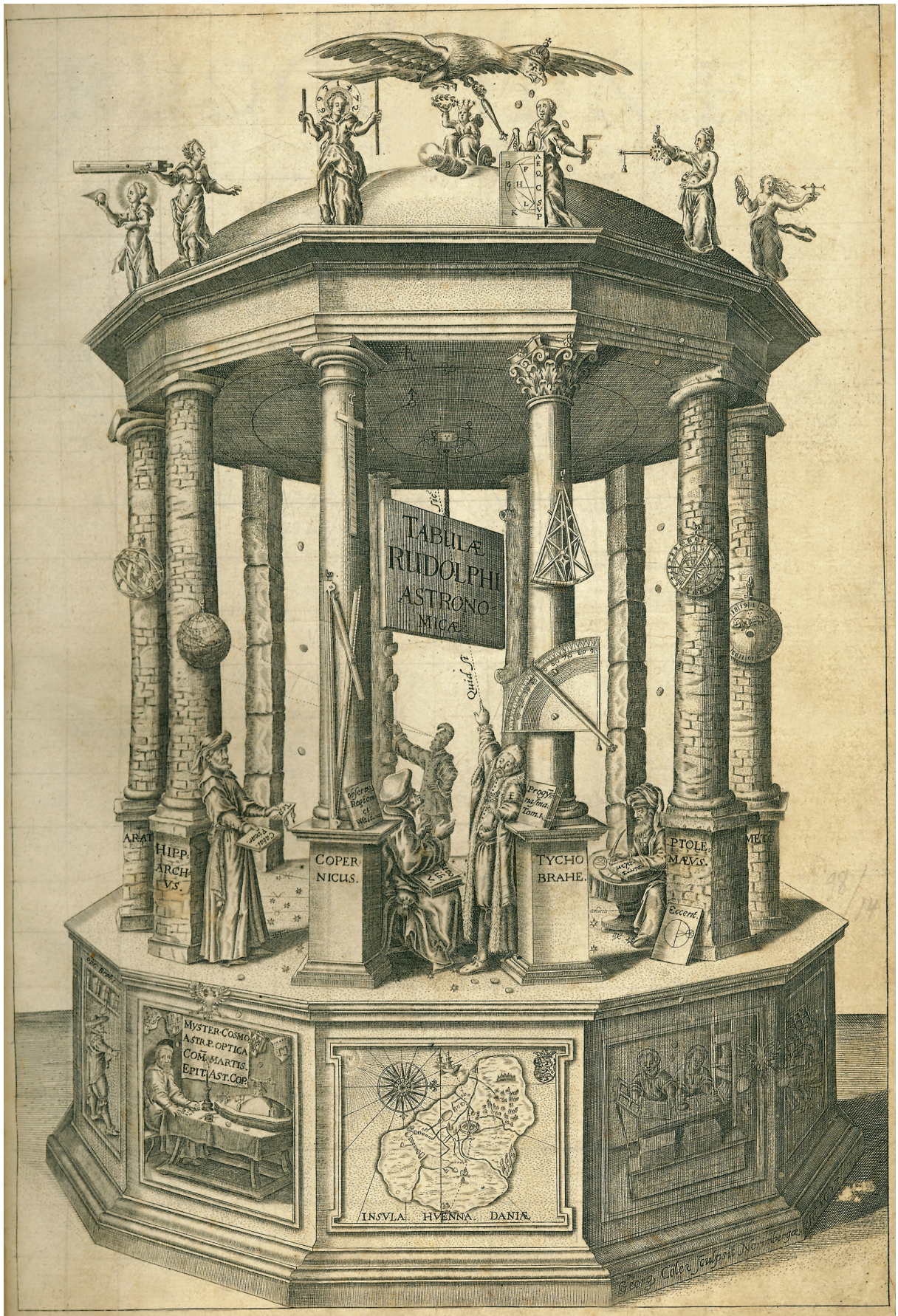

FigURE 1. Clear copy of the cover: Frontispiece designed by Johannes Kepler for the Tabulae Rudolphince (the Rudolphine Tables). The Habsburg eagle is flying above the temple, and directly below it is Urania, the muse of astronomy. Arrayed around her above the front columns of the temple are six more muses: Physica lucis (at left), Optica, Logarithmica, Doctrina triangulorum, Stathmica, and Magnetica. Within the temple we see an ancient astronomer (back center), then (from left to right) Hipparchus, Copernicus, Brahe, and Ptolemy. Kepler is modestly positioned on the base of the temple in the second-to-left panel. 
showed an interest towards science, mostly in the form of astrology and alchemy, but he also showed growing symptoms of mental instability. Now Rudolph was in need of a new imperial mathematician. After swallowing his aristocratic feelings, Tycho Brahe accepted the job with a sense of relief and became an employee for the first time.

Tycho had by this time realized that neither he nor his assistants could find coherence in all the observations he had collected. He thought he had seen something special in the speculative mind of a young Protestant school teacher and district mathematician in Graz by the name of Johannes Kepler. In the Roman Catholic city of Graz, the last Protestants were finally ordered to leave town. Kepler travelled to Prague in hopes of a secure position and the most precious thing in his world-Tycho's observations. After some personal friction and scientific disagreement, Tycho decided to introduce the disillusioned Kepler to Emperor Rudolph. At an audience in September 1601 the three men met and Tycho suggested a glorious new project, to be entitled the Rudolphine Tables. Everyone was pleased, and so it happened that the two Protestant scientists were engaged in the Roman Catholic imperial epicenter of Prague. But just a month later Tycho Brahe died unexpectedly. It was promptly decided that Kepler was to take over Tycho's position, and his main task was to compile the Tables. He successfully managed to achieve this goal, but the book was not published until 1627. In the meantime Kepler had several problems and conflicts to manage: fighting with the Brahe heirs who watched over their interests; inventing a new planetary theory and other methods to improve accuracy and facilitate the reading of the Tables; procuring a salary from the imperial treasury for his family to survive; dealing with many personal disappointments; carefully maneuvering both in war conflicts and around three successive emperors; and curbing his love for new mathematical speculations.

The Rudolphine Tables were the first set of astronomical tables that allowed one to calculate the position of the planets even in the far future with an accuracy sufficient to make reliable predictions. To be sure, there were earlier tables much resorted to by navigators, astronomers, and astrologers, but regardless of what model they were based on, their predictions gave errors of up to five degrees. (For comparison, the angular diameter of the moon is around half a degree.) The predictions made from the new Tables, however, proved to be 30 to 50 times more accurate. The astronomical tables themselves did not state any positions at a certain day, but they served as the basis for annual ephemerides which provided calculated daily positions of celestial objects.

This is the only book by Kepler to carry an elaborate frontispiece, and he designed it himself (see Figure 1). By taking a tour around the picture, we may see how Kepler pays tribute to his astronomical predecessors. At first sight the impression is that he portrays himself in a very unobtrusive or even submissive way. It is true that he wanted to give prominence to Tycho, and that he was under pressure from the Brahe family to do so. However, after a closer look we will discover that Kepler, with subtle methods, often manages to emphasize his own achievements and hardships. After the title pages of the Tables there is a long hexameter poem by Kepler's Latinist friend Johannes Hebenstreit. It is a complimentary idyll, steeped in mythology, but does not always follow the frontispiece, to put it mildly.

The frontispiece nicely matches the original French architectural term designating a decorated front of a building. A frontispiece should set the character of the 
interior of a building or a book, soon to be disclosed to the eyes of the viewer or reader. In a book, it also gave a pleasant contrast to the often long and nested text following the title page.

We stand in front of a classical temple dedicated to the muse of astronomy, Urania. She is seen at the top of the dome rushing forward in a carriage. Carrying a starred crown, she seems to be searching for someone to crown with a laurel wreath. Well, there are some good candidates further down.

There are twelve columns on the high foundation, two of them hidden from our view. This corresponds to a temple shaped as a dodecagon. The twelve sides represent the signs of the Zodiac, some of them visible as sections on the floor.

The increasing solidity and elegance of the columns (proceeding from the back to the front of the temple) describes the development of astronomy from ancient times until Copernicus and Tycho Brahe. Close to the columns, some historic figures are absorbed in work and discussion. At the back, we spot a Chaldean astronomer in a Phrygian cap making observations between rough-hewn log pillars. It is in the Babylonian and Chaldean civilizations that we find many of the earliest traces of Western mathematical astronomy. Their priest-scribes compiled catalogues, recognized many cyclic occurrences, and tried to make predictions arithmetically. They observed that the movements of the planets were not uniform. To describe and explain this behaviour became the central theoretical problems for astronomers ever since the Greek era. Kepler also knew well that the sexagesimal number system had its origins in ancient Mesopotamia, and sexagesimal coordinates were something that he made frequent use of in his Tables.

The next two columns are portrayed as fragile piles of stone blocks, but proceeding to the brick pillars, we find our first two names. On the right, the name Meton sticks out. Active at the time of Socrates, he was a well-known Athenian geometer and astronomer. He tried to improve the calendar and gave name to the Metonic cycle, which is based on the observation that 19 years are (coincidentally) very close to 235 months counted as the period of the moon's phases. Many civilizations used this cycle to form lunisolar calendars. On Meton's column hangs a tribute to them: a disc divided into 19 sections, decorated with sun and moon. In Kepler's days Gregorian calendar reform was fiercely debated. Although criticized by other Protestants, both Tycho and Kepler stood up for it.

On the left side, it may at first seem odd that Kepler chose the Greek poet Aratus as one of the pillars of astronomy. Aratus is mainly known for a long didactic hexameter poem called Phœnomena ("Appearances"). This work, a blockbuster in antiquity, is actually a commissioned verse setting of treatises by Eudoxus, one of the finest Greek mathematicians and astronomers. None of his works have survived, however, and we have to rely on others to get glimpses of his contributions and brilliance. In Aratus's poem we find the first description of our familiar star constellations. Eudoxus combined a number of nested rotating spheres to represent a planet's motion around the Earth. With this clever geometric model he could qualitatively account for apparently irregular motions seen in the sky, not only deviation from the ecliptic, but also retrograde motion (where he needed four spheres). The first mathematical model combining the Pythagorean and Platonic ideas of uniform circular motions was born, the starting point of a long tradition.

Nailed to Aratus's column is an old astronomical instrument, the armillary sphere. The Earth in the middle is surrounded by the equator, the ecliptic, and 
other great circles of interest. It was widely used as a quick and simplified way to determine celestial positions in various frames of reference. Look at the flag of Portugal and you will see another example honouring a seafaring nation.

While the last two brick columns were associated with the foundations of astronomy in the Greek-speaking world, the next two represent the culmination.

The armillary sphere can be seen as a skeleton version of the celestial globe displayed on the neighbouring column of Hipparchus. The smooth surface could show the stars and the constellations (seen from outside), all often designed as a work of art. Being a skilled observer, Hipparchus compiled a famous catalogue around 130 BC with hundreds of star positions, which was not surpassed, in its essence, until Tycho Brahe's observations. Kepler made the lost catalogue appear again in the picture, where Hipparchus carries in his right hand a book with the Latin title Catalogus stellarum fixarum. In his left hand, we see a document labelled Test. with two affixed seals. The title could be short for Testimonium or Testamentum, a testimony or legacy not only of the influential contributions made by Hipparchus himself, but also of observations and views by his predecessors. These led Hipparchus to the discovery of precession, which we would now describe as a slow change in the orientation of the Earth's axis of rotation. We should also honour him as the founder of trigonometry: the first trigonometric table listed chord length as a function of the central angle.

Around the middle of the second century AD, the most important astronomical book that survived the turmoils of antiquity and its aftermath appeared. With Ptolemy's Almagest we have for the first time a table and parameters that allowed the reader to calculate the heavenly motions. The author also presented a coherent geocentric model of the known universe based on his own and earlier observational data.

Ptolemy, like a true mathematician, is sitting writing on the tablecloth, with his book close at hand, and we see one version of the Greek title, Megale syntaxis. Our current English title, Almagest, goes back to the mixed Arabic name meaning "the greatest". A small figure can be discerned on the table: a quadrilateral inscribed in a circle. Apparently Ptolemy has just discovered his powerful theorem saying that the product of the two diagonals equals the sum of the products of the opposite sides. With its help he would generate a famous trigonometric chord table from a few basic chord values known since Euclid.

On a stone tablet leaning against the pedestal, there is an illustration of the three mathematical "e"-constructions used by Ptolemy and his forerunners: The planet moved uniformly on a small circle called an epicycle, the center of which revolved along a larger circle. If the Earth was outside the center of this larger circle, its position was called eccentric. The most controversial trick used to account for the variation in a planet's angular speed was to make the motion along the large circle uniform only when seen from another point, called the equant, different from the center and the Earth. Much of Ptolemy's impressive, but incorrect, conception of the world was adopted by scholars and the Christian Church, but with the decline of the Hellenistic culture and loss of many of its texts, these ideas fossilized during the early Middle Ages.

The handy flat instrument on Ptolemy's column is a version of the celebrated astrolabe. It was a versatile predecessor of the simple didactic planisphere, or (why not) an analog smartphone in antiquity and the Middle Ages. Ptolemy used and 
described the astrolabe, which was basically a plane model of the sky through stereographic projection, with nested revolving plates attached.

Continuing on to the two most elegant columns at the front, there are but a few steps, though it calls for a giant leap in time. Copernicus is sitting close to a Roman Doric column. Right above him hangs an instrument that goes back at least to Ptolemy, but which Copernicus described in his famous book De revolutionibus orbis coelestium, lying in his lap. It was called a triquetrum, a practical design for reading the altitude of objects from the horizon. Further up we find a long cross. Although Copernicus had official positions at the cathedral in Frombork for most of his life, he never became a priest. So we should rather understand the cross as another instrument to measure altitudes and angles, known as a cross-staff or a Jacob's staff. The simplicity made it popular with navigators.

Copernicus conducted many observations from his Frombork tower, still with quite primitive instruments. But as recorded through the manuscript at the base of the pillar, late in his life he was also presented with a large stock of unpublished planetary observations made by the two fifteenth century Nuremberg astronomers Regiomontanus and Bernhard Walther.

For more than thirty years Copernicus developed his new model with the Earth both rotating around its axis and revolving around a static sun. In 1543, the last year of his life, he was finally persuaded to print the book De revolutionibus. Even though it is clear that he meant to describe the physical reality, there were several reasons why the theory was treated as another convenient hypothesis for mathematicians to work out the planetary motions. This was the tradition for all earlier models, and the church authorities were satisfied as long as it remained so. But even most scientists were not yet convinced. Theoretically, it was not much simpler than the more intuitive geocentric model. Copernicus had still felt the need to employ a system of circles and a few epicycles, as did Ptolemy. And practically, the observations available at this time, which should confirm a correct model, were simply not accurate and systematic enough.

Tycho Brahe had advocated his own model to account for the planetary motions, a kind of compromise between the Ptolemaic and Copernican ideas, known as the Tychonic system. The Earth is still at the center with the sun revolving around it, but the other planets move around the sun. In the picture we can see Tycho pointing at the model adorning the temple ceiling while trying to persuade Copernicus, Quid si sic? ("What about this?") This question appears less innocently in a popular emblem book from 1611 by Gabriel Rollenhagen (familiar to Kepler). An emblem was a picture accompanied by a short aphoristic text. In this particular one, a dwarf on stilts looks at his mirror image, and the text where he poses the question ends with the morality "art can never improve on the wisdom of nature".

But the scene in the Tables frontispiece actually went back to Tycho himself. There are descriptions of the interior of his half-subterranean observatory Stjerneborg on Ven. There in an ornamented, heated, central room, the Tychonic model could be seen from the cupola-ceiling. Much in that room, such as allegorical figures, paintings, and inscriptions, must have inspired Kepler to the frontispiece, even though he never saw the room. Beyond seven paintings of astronomers from antiquity to Tycho himself, a yet unborn, messianic figure called Tychonides was portrayed, with the Latin inscription "that he might be worthy of his great ancestor"! 
In the frontispiece Tycho Brahe is leaning against the most decorated Corinthian column. After complaints from the Brahe family, he is now dressed in his well-known ermine robe with the collar of the Order of the Elephant around his neck (the highest order in Denmark). We see one of his books, the Progymnasmata, which described his planetary theories and contained the new star catalogue. Kepler completed and published the book in 1602 after Tycho's death.

On the column, we see two instruments which Tycho had developed and improved in order to attain better precision and stability. A breakthrough was the Medium-Sized Quadrant from 1580 made of solid brass, just above his head. He also constructed a number of sextants with $60^{\circ}$ arcs which were mainly made of wood. They were often light and portable, but later he made them larger and fixed, like the Triangular Sextant from 1582 further up on the column. (It looks rather like a $45^{\circ}$ octant here, but we look at it slightly from the side!)

These instruments were used on the isle of Ven, which is prominently displayed in the central panel of the foundation with the castle in the middle. According to Hebenstreit's poem, the important base meridian used by Tycho and Kepler is shown. The dashed line in the picture, however, is if anything perpendicular to this meridian, since the north is directed towards the right, as the compass rose correctly shows.

In the panel to the left we finally catch sight of Kepler himself. By candlelight, tired and dressed in nightwear, the protagonist looks at us, perhaps asking for pity. The long hours have taken their toll on him. Only a few coins from the Habsburg eagle have reached his table, but he is the proud architect of the temple. On the table lies a replica of the dome, where he displayed his skills as the culmination of the tradition below, as we shall see. On the wall are four titles of his major works and four city coats of arms, representing Bohemia, Prague, Upper Austria, and Linz (where Kepler moved in 1612).

In the adjoining panel, one of Tycho Brahe's heirs points upwards at Tycho's observational records and to the right at Kepler. The two panels at the other end refer to the printing of the book (in Ulm). In between them the double-headed Habsburg eagle grants the printing privilege. Below we are told that Georg Cöler engraved the frontispiece in Nuremberg.

At the top we see six scientific muses bordering the dome, all at the service of Queen Urania above them. Such allegorical figures were abundant in medieval and Renaissance illustrations, typically personifying the seven liberal arts which formed the educational canon. Kepler here instead invokes a different set of sciences covering important discoveries, inventions, and ideas in his career.

We start at the right side of the dome with the charged figure of Magnetica holding a lodestone and a compass. Already in his first work Kepler had insisted on a physical cause of planetary motion. Earlier it was argued that you could not, or at least should not try to, figure out the physical grounds. Kepler, with his firm belief that all the planets orbited the sun in almost the same plane, thought that such a force must emanate from the sun. And without the unifying theory of gravity and the conception of inertial motion, he turned to magnetism. This was the force in vogue at a time when the Earth had recently been found to act as a giant magnet. The rotation of the sun and the magnetic interaction between sun and planet caused the planet to orbit the sun, Kepler proposed. Even though these physical speculations, and other neo-Platonic ideas based on simplicity of natural 
laws, were wrong, the argument of a sun-centered force had put him on the right track.

As a consequence Kepler also insisted that the Earth in his model should behave just like the other planets. Some traditional Earth-specific features could still be seen in Copernicus's theory, but Kepler now exploited all aspects of heliocentrism. In this way the assumptions became simple, natural, and uniform, though it turned out that he had to invent new techniques and go through long and complicated calculations in order to truly describe the orbits. The focus was on the planet Mars. Kepler's "warfare on Mars" engaged him between 1600 and 1605, and the process has been called "the birth of the scientific method".

In his first attempts he tried to keep a circular orbit for Mars around the sun. To account for the observations, he put the sun a little off center, and on the opposite side he reinserted an equant; i.e., seen from this point Mars moved uniformly. Even though he varied the relative distances of the sun and the equant from the center of the orbit, the model refused to come sufficiently close to Brahe's trusted observations. If the distances were equal, however, he noted that Mars' linear velocity seemed to be inversely proportional to its distance from the sun. This distance law was strictly valid only when the planet was furthest from or nearest to the sun, but he hypothesized the rule for the whole orbit. Later he found the correct rule by substituting the linear velocity with its component perpendicular to the radius vector from the sun. From the distance law it was theoretically possible to determine the position of Mars in its orbit at a given time. With no calculus available, but inspired by ideas from Archimedes and Nicholas of Cusa, he first resorted to numerical summation to compute an elliptic integral and then solved the inverse problem by interpolation. The calculations became exceedingly laborious, but he found a shortcut by summing areas instead of distances: the line joining a planet to the sun sweeps out equal areas in equal time. It has become known as the area law or Kepler's second law. Sector areas in an eccentric circle were known, and the calculations could be simplified. Typical is Kepler's use of conjectures which, even if not completely accurate, led him forward to new discoveries and relations, from which he could go back and modify the conjectures and their connections. The level of proof was set by Tycho Brahe's observations and the requirement that all motions should be physically natural.

The next muse, Stathmica (second from right), is meant to illustrate the area law. She holds a steelyard balance. The sun is at the fulcrum and (instead of a fish and some weights) two planets are hanging so that the system is in equilibrium. This is a simplified version of a figure in Book IV of Epitome astronomiae Copernicanae (1621), the full and mature outline of Kepler's achievements and the basis for the Tables. His idea of how the motion of a planet is balanced under the force from the sun is symbolized in this simple figure. We may also see both the law of the lever and Kepler's area law as expressing the principle of conservation of angular momentum. Newton later showed the area law to be valid under any central force.

Implicit in Kepler's models thus far had been the traditional assumption that the Earth moved in an eccentric circular orbit, but uniformly with respect to the center (i.e., no need for a distinct equant). He set as his next task to find out whether this was really true. The determination of a planet's orbit around the sun required of course a proper description of how the Earth moved. By a famous new method in which he used specific Mars observations from Tycho's abundant data, Kepler 
found that also in the case of the Earth the equant point had to differ (slightly) from the center of the orbit. Now he used this better approximation of the Earth's orbit, together with the area law, to continue his attack on Mars.

But with its larger eccentricity, the circular orbit model for Mars still refused to agree with Tycho's observations. It took Kepler two more years to finally arrive at the correct elliptic orbit. It was clear that the circle had to be compressed to an oval of some kind. He first tried with the boundary of an asymmetric two-dimensional egg, since this path could be generated by an (old-style) epicycle. He approximated this oval with an ellipse in order to more simply use his area law; sector areas were explicitly known for ellipses since antiquity. Finally, he found a close fit when he chose a new ellipse halfway between the circle and the approximating ellipse.

He might have stopped here and triumphed. But just as when he abandoned the circle, he still did not understand how an elliptic orbit could be physically motivated. As a fortunate consequence of the further pursuit, he arrived at an explicit construction of the orbit. An opening came when he noticed a striking geometric expression for the distance between the sun and a specific position of Mars. Again he could make a natural generalization of this expression around the whole orbit, representing the distance as a function of the orbital angle he had used before, the so-called eccentric anomaly. This angle was measured at the center along the eccentric auxiliary circle. He was disappointed to find that the orbit (called the via buccosa) did not comply with the observations sufficiently well, and it was not even an ellipse. Struck by a last brilliant idea, Kepler now realized that he could represent the sun-to-Mars direction by another generalization, and still keep the earlier relation between distance and eccentric anomaly. In technical terms he had redefined the relation between the eccentric anomaly and the true anomaly (the angle of the Mars position seen from the sun). And this time the calculated orbit was in accordance with Tycho's data. He could also prove that the curve was an ellipse with the right eccentricity, and he claimed that, as described, the ellipse had physical grounds. (It was shown much later that also the via buccosa actually fulfilled all of Kepler's criteria. He seems to have made an incorrect implicit assumption which caused the discrepancy. Perhaps Kepler would have attacked and resolved this problem as well, had he been aware of it! At least one can say that he had taken his theory down to the very limits of Tycho's observations.)

Kepler was ready in 1605 to publish the new results. In the exceptional book Astronomia nova he included also the setbacks and failures along the road to the ellipse. Conflicts with the Brahe family and financial problems delayed the printing until 1609.

In the right center position on the dome, the muse known as Doctrina triangulorum (the science of triangles), i.e., trigonometry, reminds us of Kepler's first law, as it was later called: planets move in ellipses with the sun at one focus. In a firm grip she holds the traditional square and compasses. In front of her we see a figure which Kepler used to describe and determine his last ellipse. It is shown dashed inside its auxiliary circle. The sun $S$ is at a focus, and some positions of Mars are designated by $F, H$, and $L$ along the ellipse. Later in the book, in Chapter 20 of the explanatory notes before the actual tables, Kepler refers to this tiny figure found only in the frontispiece!

Just above, you cannot miss the Habsburg eagle hovering over the dome. Rudolph II and the two succeeding emperors here got their due share. The bird of 
prey generously drops coins from its beak, which we may follow down through the temple.

The fourth muse in the left center position bears the name of Logarithmica. For Kepler it seemed as though the heavens repaid him for his efforts when he heard of Napier's invention of the logarithms in 1617. He understood at once their importance and how much time and effort would be saved in the computations necessary for his Tables, and he became the first to apply logarithms on a large scale. Napier's second book, which explained the construction, had not yet appeared, so Kepler began to develop his own theory and logarithmic tables. He derived the independent heavy construction from Euclid's theory of proportions. Theory and tables were published in two books a few years later. For the convenience of the reader, Kepler cleverly included two logarithmic tables in the Rudolphine Tables as well. Take a look at the halo above Logarithmica's head where the number 69314.72 shines. We recognize it today as a multiple of the basic $\log _{e} 2$. Actually, Kepler's first table gives $-10^{5} \log _{e} x$, while the second tabulates $-10^{5} \log _{e} \sin y$. So $x=\frac{1}{2}$ and $y=30^{\circ}$ give the logarithmic value in the halo. The lengths of the two rods that muse Logarithmica carries are in proportion $1: 2$. In music theory, this ratio corresponds to the basic octave interval. Such harmonies always played a vital role in Kepler's thoughts.

It is interesting to note that it was when Kepler learned and thought about the new logarithms that he also discovered his so-called third law: for any two planets the squares of their orbital periods are to each other as the cubes of their mean distances from the sun. Kepler's mind was now open to thinking in terms of geometric sequences.

The last two muses both reflect the fact that Kepler wrote two books which laid the foundation for theoretical optics. You do not hear much about this since he neither invented the telescope (he had bad eyes) nor discovered the exact law of refraction (he only needed a good approximation). Descartes and others later acknowledged Kepler as the master of optics. Early questions regarding eclipses and refraction led Kepler to write the first modern book on optics, Astronomiae pars optica (1604). This was done in the midst of his intense Mars studies. He also came up with novel ideas about conic sections when he treated curved mirrors.

On the far left, the radiating head of the muse Physica lucis et umbrarum ("the physics of light and shadows") seems to cast a shadow cone behind the sphere in her right hand. The sphere and shadow also bear some resemblance to a comet with a tail. Among the several comets Kepler observed and described during his life, one was sighted in 1607 . It was to reappear 75 years later and became known as Halley's comet.

The muse Optica (second from left) exhibits a telescope of an odd rectangular form. In 1610 Kepler first heard of Galileo's telescope and what it had revealed about the heavens. Again he had immediately recognized and acknowledged a new revolutionary invention. As with the logarithms he wrote an important treatise, Dioptrice, explaining mathematically how light passed through systems of lenses, especially in Galileo's magical tube. He went on to design a new type of telescope with a convex lens also for the eyepiece instead of Galileo's concave one, which allowed for higher magnification. 
With unflagging enthusiasm Hebenstreit reveals in the poem that behind the dome, out of our sight, there are six more muses personifying other sciences which had engaged Kepler's thoughts.

When you look at a page in the Rudolphine Tables, give a thought to the mathematical and astronomical symbols. These special printing types were precious to Kepler. He only had confidence in his own set, which he carried around from city to city in the 1620 s when the war came closer.

Shortly before his death in 1629 Johannes Kepler published a little pamphlet where he pointed out that two years later at specified times both of the inner planets, Mercury and Venus, were to pass across the face of the sun. He also described how to observe these events for the first time. The prediction of the Mercury transit in 1631 could be seen in Europe, and it turned out to be correct within a few hours.

More and more people accepted that at last someone had figured out how our planets move in the sense that meaningful predictions could be made. On planet Earth the Thirty Years' War still raged. In a few years, a young man would be seen sitting under an apple tree, perhaps in the orchard around Kepler's temple, pondering over how to further embellish the temple and explain its construction. But that was a constellation the Rudolphine Tables could not predict.

Institut Mittag-Leffler, AuravÄGen 17, SE-18260 Duursholm, Sweden

E-mail address: ragstedt@mittag-leffler.se 